\title{
PERCURSO de VIDA QUE FAZ O GÊNERO: REFLEXÕES ANTROPOLÓGICAS A PARTIR DE ETNOGRAFIAS DESENVOLVIDAS COM PENTECOSTAIS NO BRASIL E EM MOÇAMBIQUE
}

Clara Mafra

Ele me olhava. E eu não soube como existir na frente de um homem. Clarice Lispector

O corpo noutro corpo entrelaçado, fundido, dissolvido, volta à origem dos seres, que Platão viu completados: é um, perfeito em dois; são dois em um. Carlos Drummond de Andrade

\section{Introdução}

Até meados do século passado, Europa e Estados Unidos eram as referências sociais consolidadas para se pensar o fenômeno do cristianismo no mundo. Atualmente, os cientistas sociais são obrigados a constatar que a geopolítica do cristianismo foi invertida: as maiores populações cristãs encontram-se ao sul do globo e não mais ao norte. 
Essa inversão geopolítica provocou um aumento considerável dos estudos do cristianismo na última década (Robbins 2004; Cannell 2006; Freston 2010; entre outros). Nesse quadro, boa parte dos pesquisadores passou a perseguir a questão da especificidade do crescimento e a questionar por que, entre tantas possibilidades de desenvolvimento do cristianismo, é justamente o pentecostalismo que tem sido mais aceito pelas populações?

Entre as muitas explicações disponíveis, criou-se um razoável consenso na literatura apontando a teologia da Batalha Espiritual como quesito central para o sucesso proselitista do pentecostalismo. Por que a Batalha Espiritual seria tão central? Segundo Joel Robbins, isso acontece porque o pentecostalismo opera como "como um repositor de um dualismo encantado, que serve estrategicamente para capturar cosmologias tradicionais e as atacar, alterando profundamente o modo como estas são compreendidas" (Robbins 2004, tradução livre). Nessa linha interpretativa, é suposto que o processo de conversão ao pentecostalismo envolva uma recategorização da cosmologia de pertencimento anterior do fiel: o que inicialmente era uma entidade divina, torna-se, pelo trabalho de conversão, uma entidade demoníaca. Isso significa que a operação da conversão diz respeito ao aprendizado de uma nova classificação e um novo mapeamento de mundo, algo que normalmente será transmitido pelo trabalho missionário - i.e., pelo ideólogo engajado na tarefa proselitista.

Apreendida a nova decodificação de mundo, os deuses que o neófito conhecia, são realocados na nova grade classificatória como demônios para serem daí recusados. Um processo de conversão bem sucedido envolve, nessa interpretação, uma substituição de taxinomias e um afastamento radical do modo anterior de apreensão de mundo (esse afastamento, porém, tem sido muitas vezes posto em suspenso, na valorização de processos de mútua fertilização e de hibridização). De qualquer modo, supõe-se que o grande ganho do pentecostalismo está não necessariamente na recodificação de mundo, mas no fato de que a nova taxonomia permite uma integração mais fácil e ágil entre ordem local e ordem global, uma vez que a modernidade ocidental foi originalmente constituída a partir de um projeto de redenção cristão. Em poucas palavras, o grande ganho da conversão estaria, nesta interpretação, em uma integração sistêmica entre as gramáticas culturais locais e transnacionais.

Em outro artigo, eu discuti que essa visão inverte o sentido do dualismo pentecostal e carismático (Mafra 2012). Argumentei que o dualismo pentecostal e carismático não vem para produzir um conhecimento que categoriza e mapeia o mundo, revelando sua verdade supostamente essencial estabelecida no início dos tempos, mas vem como uma imersão em uma trajetória de vida formada sob os parâmetros de uma interlocução ampliada com o entorno de materiais, humanos e sobrehumanos. No presente artigo, quero dar mais um passo na compreensão do dualismo pentecostal processual, sugerindo que, como em seu percurso de 
conversão o crente não tem um "mapa", a marcação a que o novo convertido é instigado a prestar atenção é a da descoberta do gênero em si. Na concepção pentecostal, um percurso de vida percorrido a partir da referência bíblica constituirá um corpo e uma subjetividade de gênero que acolhe a alteridade amorosa. Sigo aqui uma pista dada por meus interlocutores pentecostais: segundo dizem, um dos primeiros frutos do Espírito Santo é o alcance de uma identidade feminina e masculina plenas.

Isso tem importância no estudo comparado do pentecostalismo. De que modo? Por exemplo, recentemente, na tese Violent Conversion - Brazilian Pentecostalism and the Urban Pioneering of Women in Mozambique, Linda van de Kamp (2011) se contrapôs aos argumentos centrais dos estudos sobre pentecostalismo e gênero na América Latina, que tendem a concordar que o pentecostalismo é um modo bem sucedido das mulheres lidarem com os impasses e tensões dos processos de modernização e globalização. A autora reconhece que os missionários brasileiros que foram para Moçambique ensinar o evangelho acabaram incentivando as mulheres a uma atitude de pioneirismo social ao promover a mudança de atitudes, o aprendizado de novas disciplinas e a construção de planos alternativos de casamento, família e carreira. O trabalho, porém, baseado em uma pesquisa de campo realizada ao longo de mais de dois anos, em Maputo, defende que esse pioneirismo apresenta dimensões claramente violentas, que facilmente desembocam em um aumento de incerteza social e de mobilidade social descendente. Em alguns casos, quando as mulheres pentecostais entram nas campanhas da Fogueira Santa da IURD (Igreja Universal do Reino de Deus), buscando novas bênçãos, muitas vezes elas acabam por fazer uma doação tão extraordinária de recursos para a igreja - um Potlach - que resulta no rompimento das expectativas usuais de reciprocidade já estabelecidas nas redes sociais em que se inserem. Em outros casos, quando as mulheres entram em rituais de exorcismo, na busca de libertação dos "maridos espirituais" que as aprisionam, elas acabam por levar "surras no espírito" e a demonizar os seus parceiros e as pessoas próximas, afastando-as. Em geral, argumenta a autora, os vínculos das novas convertidas com suas famílias extensas e/ou seus companheiros tornam-se, depois da conversão, mais frágeis e inconstantes, algo que aumenta a percepção de medo e solidão destas mulheres.

De acordo com Linda, o pentecostalismo provocou problemas humanitários severos em termos de gênero em Moçambique, o que, no entanto, não impede que esse mesmo pentecostalismo continue a atrair multidões. As mulheres moçambicanas são atraídas pela IURD, igreja que procuram para resolver seus problemas, mas acabam, muito frequentemente, tornando-se elas mesmas "pessoasproblema". É como se as moçambicanas aprendessem a Batalha Espiritual como uma luta que não tem fim, que cresce em espiral indefinidamente, destruindo em sua trilha os vínculos dessas mulheres com os seus parceiros amorosos e suas 
extensas famílias. A sociedade moçambicana, por sua vez, parece aceitar a convivência com essa "conversão violenta" que se processa entre suas mulheres.

Acredito que a pesquisa antropológica comparada nos ajudará a adensar a compreensão dessa entrada violenta do pentecostalismo em Moçambique. Como desenvolverei ao longo do artigo, argumento que a falta de referências no cenário cultural moçambicano do amor romântico e de um Deus Todo Poderoso e Amoroso (Veyne 2007) tornaram a Batalha Espiritual, naquele contexto, uma trilha que se percorre às cegas. Sem referenciais cristãos culturalmente mais estáveis, as mulheres moçambicanas convertidas passaram a se engajar em lutas sem propósito - ou com propósitos demais.

Inicio este estudo comparado introduzindo o leitor a algumas características do cristianismo no Brasil, onde uma grande reverência com a Santidade (Mafra 2011) convive com noções de fluxo, movimento e interlocução.

\section{As imagens que falam mais que palavras}

Não haveria cristianismo se os problemas da finitude humana e do enfrentamento da morte não tivessem sido respondidos de modo singular, conjugando aspectos do farisaísmo e da filosofia grega (Segal 2004). Poucos antropólogos, porém, deram importância à diferença de abordagem do problema da finitude humana entre, por exemplo, evangélicos reformados e pentecostais contemporâneos. Supõe-se que, fazendo parte da mesma tradição religiosa, os pressupostos de uns valham para os outros, ou então que, no compartilhamento parcial de alguns pressupostos da ciência, os crentes insistam no esquecimento do morto e na ruptura da relação vivos/mortos, ratificando processos de desencantamento de mundo (Vicente da Silva 2011).

Felizmente, em minhas pesquisas acabei encontrando duas pinturas que, do meu ponto de vista, explicitam de modo precioso a enorme distância entre as concepções de salvação entre católicos e pentecostais. Nos próximos parágrafos, convido o leitor a me acompanhar na observação dessas pinturas, na esperança de que, em sua contemplação, convença-se, tal como eu me convenci, que mesmo cristianismos tão próximos como o catolicismo e pentecostalismo, apoiamse em concepções razoavelmente distintas de cosmos e de salvação - algo difícil de se apreender em palavras, mas revelador em imagens. São diferenças que não necessariamente seguem as ortodoxias religiosas, mas que também não abrem mão de uma interlocução com elas.

Antes de apresentar as pinturas propriamente ditas, devo dizer algumas palavras preliminares sobre a escolha delas. Em um país de longa tradição católica como o Brasil, são diferentes as condições de produção das pinturas religiosas: enquanto a arte com referências católicas é abundante, variada e abrange um leque amplo, indo da mais alta qualidade artística ao mais evidente amadorismo, 
a arte pentecostal é quase invisível, rara, e singularmente amadora. A situação tem a ver com a tradição iconoclasta reformada, que teve seu impacto inclusive no pentecostalismo regional. Por isso, quase não temos registro e reflexão sociológica sobre os raros trabalhos iconográficos porventura localizados. Um artigo curto, mas primoroso, foi escrito por Douglas Teixeira Monteiro (1975), analisando uma imagem muito divulgada nas campanhas de evangelização das missões protestantes no início do século XX. Trata-se do quadro "Os dois caminhos" ou, na versão clássica, "O caminho largo e o caminho estreito". A imagem, entretanto, como Douglas afirma, tinha muito pouca relevância em São Paulo, nos anos 1970. A vocação iconoclasta da denominação já tinha trabalhado no sentido de minimizar a sua importância.

Em minhas pesquisas entre pentecostais, encontrei raríssimas imagens, mas quando as localizei, procurei registrá-las. Este foi o caso da Figura 2, uma fotografia que tirei quando visitei a Igreja Assembleia de Deus de Guajaramirim, Rondônia. A imagem está em continuidade com uma tradição regional de murais nas fachadas de bares, restaurantes, barbeiros, cabeleireiros, borracheiros, geralmente adornando o lugar fazendo referência à flora e à fauna regionais. Penso que exatamente por encontrar ressonância na cultura regional ainda é possível localizar painéis como este que apresento, com imagens de rios e cascatas contornando o lugar do batismo por imersão da igreja. Em outros estados que visitei, as pinturas eram substituídas por fotografias. Isso tudo para dizer que, na minha seleção das duas pinturas, escolhi uma entre muitas - pintada por uma artista católica, Rosina - e outra, entre poucas - pintada pelo irmão cujo nome, acredito, seja Carlos.

Além disso, como não conheci pessoalmente os artistas e tenho pouquíssimas referências sobre suas biografias, optei por não tecer considerações sobre as diferenças de gênero dos artistas e/ou o impacto da questão de gênero nas obras. Sei que este não é o procedimento metodológico mais adequado, mas foi o possível nas circunstâncias de escrita.

Comentando diretamente as pinturas, vale mencionar que ambas são classificadas entre estudiosos da área de artes plásticas como de arte naïf, pois realizadas de "modo ingênuo ou primitivo por pessoas comuns e amantes da pintura sem pretensão de profissionalismo" (Filkenstein 2001:22). A primeira pintura (Figura 1) foi realizada em 1978, por Rosina Becker do Valle, em tela de eucatex, intitulada "Festa de São Sebastião". Segundo a curta biografia que acompanha seus trabalhos, Rosina foi dona de casa e sempre viveu no Grajaú, no Rio de Janeiro. Aos 41 anos, em busca de "distração", começou a pintar e nunca mais parou. Nascida em 1914, ela faleceu no ano 2000. A segunda pintura (Figura 2) foi realizada pelo irmão Carlos, que assina abaixo de uma inscrição de "Glória a Deus!", em um mural que ladeia a piscina batismal da Igreja Assembleia de Deus de Guajaramim, em Rondônia. Retrata uma cascata 


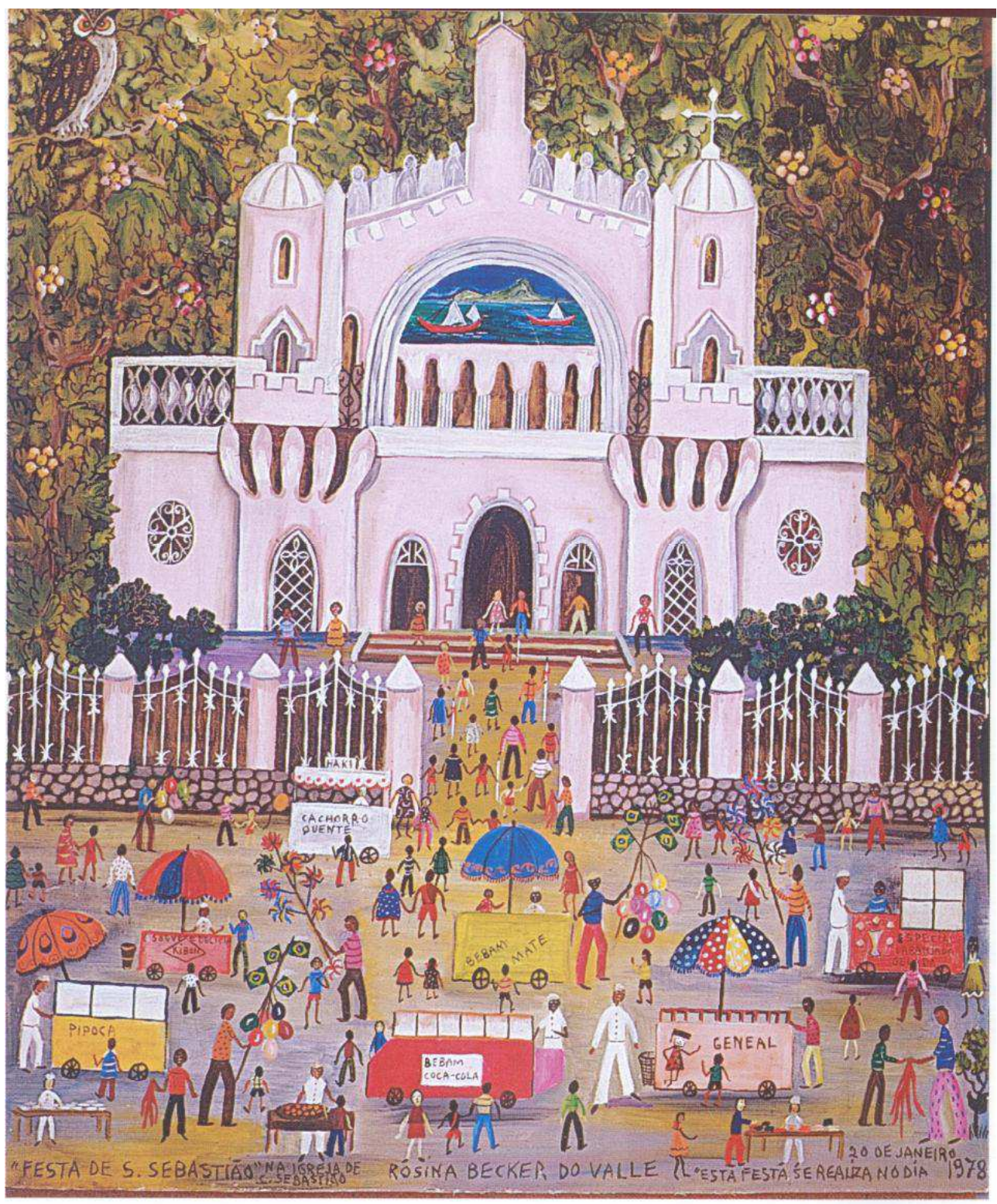

ROSINA BECKER DO VALLE - Festa de S. Sebastião, 1978 - óleo s/tela e eucatex $72 \times 59 \mathrm{~cm}$.

Figura 1 


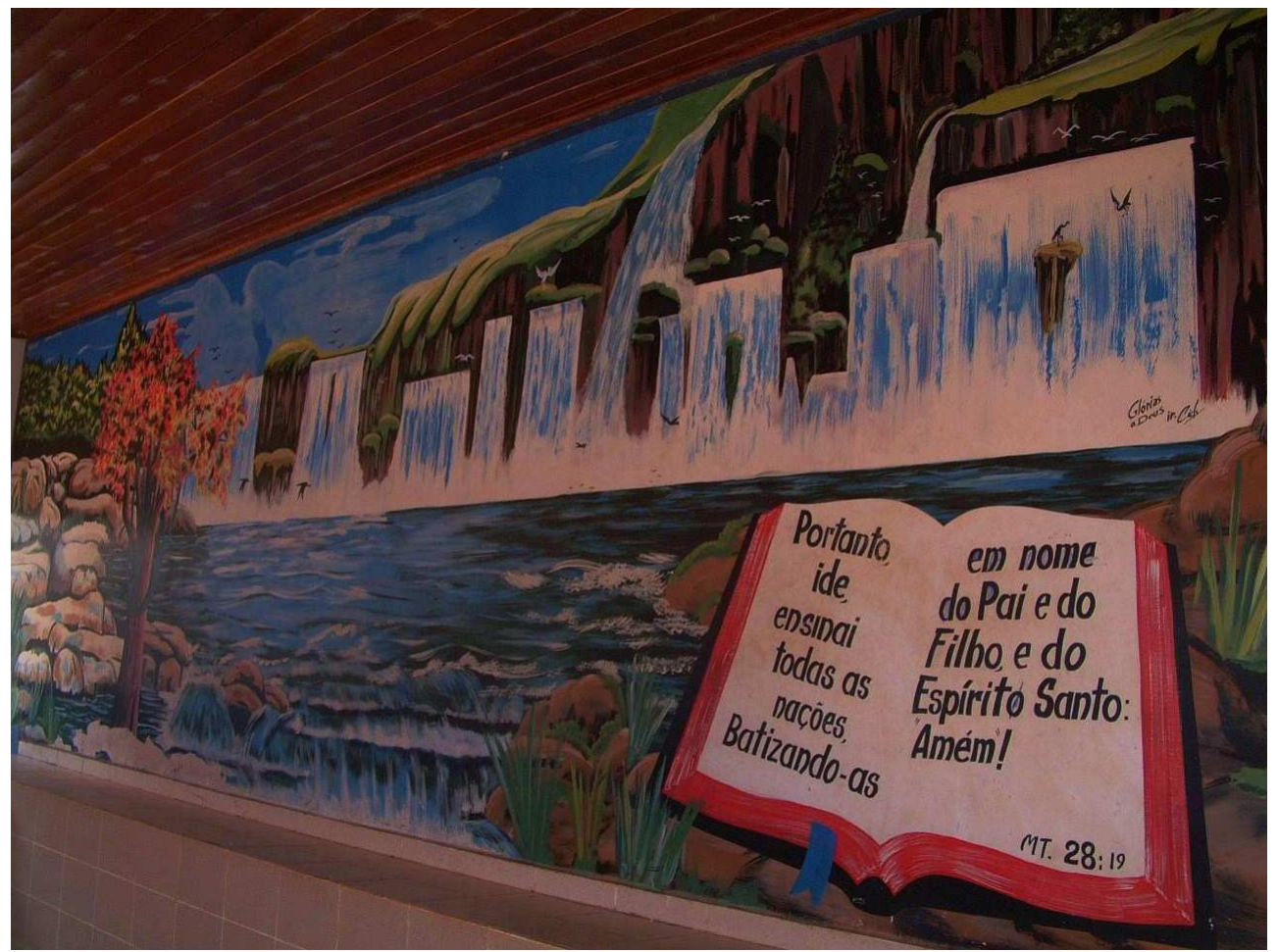

Figura 2

com catorze quedas estranhamente retas que, em uma desproporção típica de colagem, está justaposta a uma bíblia aberta. No interior do livro se lê: "Portanto ide e ensinai todas as nações, batizando-as em nome do Pai, do Filho e do Espírito Santo: Amém! Mt 28:19".

Na pintura "Festa de São Sebastião" chama atenção o colorido da festa que acontece fora dos muros da igreja. Inúmeras pessoas circulam entre as barraquinhas, comprando, consumindo, observando, brincando, comendo, bebendo. São bens variados os objetos que compõem a tela atraindo e deliciando os personagens: pipoca, refrigerante, mate, cachorro quente, queijadinha, sorvete, balões, bandeiras. A igreja em rosa - monumental - se destaca da floresta, que a circunda como uma guirlanda. Trata-se portanto, de um mundo religioso completamente culturalizado - a natureza vem como adereço de uma vida social centrada em si. Quando algum animal aparece (veja-se, por exemplo, a imagem da coruja no canto esquerdo da pintura) é apenas como símbolo do sagrado que está na proximidade. A desproporção da coruja em relação à floresta é evidência forte de seu desencaixe da cena natural e encaixe na cena simbólica. 
$\mathrm{Na}$ segunda pintura (Figura 2), os animais também são estilizados. Os pássaros que povoam a cascata são minúsculos e diversos, em cores e tamanhos diferentes, algumas vezes penetrando no seu interior, ora fazendo malabarismos no ar, e outras vezes fazendo ninhos em abrigos entre as falhas da cachoeira. As águas circulam, fazem onda, ficam calmas, alisam as pedras, avançam ameaçadoras sobre a margem. Essas margens, por sua vez, são compostas por rochas com e sem musgos, são lisas ou rugosas, são cercadas de verde ou se colocam como puro obstáculo no caminho das águas. Esses muitos e pequenos detalhes indicam que o pintor conhece bem a vida de um rio e nesse sentido, não se sente apartado da vida da natureza. Rosina, pelo contrário, contempla a natureza de fora, como um observador distante, como é de se esperar de um habitante metropolitano. Mesmo assim, para o pintor da Assembleia de Deus de Rondônia, o rio, a cascata e a paisagem natural só se completam quando justapostos ao versículo bíblico que se encaixa na pintura - ou melhor: a pintura não foi elaborada para celebrar a paisagem em si, mas para funcionar como metáfora do mundo humano harmonizado com natureza e sobre-natureza: o rio caudaloso e deslumbrante estabelece um paralelo com a mensagem cristã proselitista que transforma, através do batismo, o ser humano em emanação de água viva do Espírito Santo. Talvez o recorte reto das várias camadas da cascata explicite não apenas o caráter amador da obra, mas a busca da "vida reta" do autor pentecostal.

Nestas duas pinturas encontramos algumas distinções importantes nas representações idealizadas do mundo. Na representação de Rosina, que por uma economia de escrita vou passar a identificar como "católica", o mundo está claramente segmentado em lugares onde se desenvolvem diferentes feixes de atividade - primeiro, o mundo do escambo, da troca, da comida e da bebida; depois, um espaço entre o portão e a porta da igreja, um lugar intermediário, que organiza o fluxo disperso dos viventes em direção ao sagrado. Em seguida, sem que consigamos enxergar seu interior, coloca-se a fachada da igreja protegida por uma enorme porta de madeira que esconde o mistério dentro de si. São três camadas que se sucedem constituindo e sendo constituídas por atividades desenvolvidas pelos seres humanos. Noto que a ação dos homens, que se apresenta na pintura em toda sua diversidade e colorido - de gênero, cor, idade -, desenvolve-se do lado de fora do portão, no espaço do mundano. À medida que os seres humanos se aproximam da porta da igreja, eles já não fazem muita coisa - caminham eretos, economizam gestos, aproximam-se com alguma reverência. Entre as várias possibilidades de apreensão da obra, seu sentido dominante é revelador: os seres humanos buscam o sagrado para reencenar, relembrar, reviver a boa ordem das coisas que atravessa os tempos. Nesta representação da vida harmoniosa, como nos lembra a coruja, as pessoas devem entrar em contato com as forças que ordenam o mundo desde tempos imemoriais, reencenando a cada festa, cada aparição mariana, cada devoção, cada ritual, seu pertencimento e 
continuidade com uma longa tradição de sabedoria. Nesse sentido, os seres humanos não são exatamente agentes do sagrado, mas um sagrado que constitui e ordena a terra, alimenta os seres humanos de acordo com uma ordem prévia.

$\mathrm{Na}$ segunda pintura, o centro do quadro é ocupado por água, fluxo, corredeira. Nessa figura, não há representação de seres humanos, tanto por uma regra iconoclasta da tradição religiosa, como porque o foco do desenho está na força da alegoria. Segundo a interpretação pentecostal das escrituras, quando os homens assimilam a palavra de Deus como "palavra viva" - mensagem do Espírito Santo - eles mesmos se transformam em fluxo, em devir, em processo. Em outras palavras, os seres humanos, batizados pelo Espírito Santo reencontram o fluxo vital e passam a fazer parte ativa dele. Já a pessoa que não se dispõe a ser "vaso" do Espírito Santo interfere na circulação dessa força viva, diminuindo a exuberância da presença e reposição do sagrado no mundo. $O$ contraponto a este planeta abundantemente preenchido por águas é um planeta sem água, desértico, inabitável. Por suposto, o contraponto está fora da pintura que estamos observando, mas é referência recorrente no imaginário pentecostal.

Como a ação dos homens se encaixa nestas duas descrições de mundo harmoniosas? Na descrição de Rosina, as atividades realizadas pelos seres humanos (vender, comprar, produzir, brincar, festejar) desenvolvem-se sem interferir, afetar, requerer as coisas do sagrado. As atividades em que os seres humanos estão engajados são muitas e variadas e não afetam a totalidade do cosmos. No mundo imaginado por Rosina, o sagrado constituiu a terra em tempos imemoriais e só poderá voltar a se manifestar através de indivíduos exemplares ou em eventos milagrosos, nos santos e nas aparições, que em sua excepcionalidade são capazes de criar mediações com as forças extraordinárias do mundo. Ordinariamente, uma pessoa comum, engajada em sua vida cotidiana, apenas eventualmente entra em sintonia com esse sagrado. Para que isto ocorra, a pessoa comum deve se apoiar em rituais ofertados pela tradição religiosa (a promessa, a romaria, a procissão, a doação de ex-voto), e nessa medida, ao aderir corretamente à tradição, ganhar o acesso ao sagrado que está em outro nível. Isso quer dizer que, como consolo ou como condenação, nessa cosmologia a força vital do sagrado atravessa os tempos independentemente do caos e desventura da vida dos homens. Ou melhor, existe algo que pertence à sobrenatureza de Deus e que o humano não alcança a menos que seja projetado pela materialidade do mundo (humana e não humana) . Neste caso, a sabedoria de vida corresponde a uma busca de adequação a uma hierarquia de posição.

No contraste, no caso da pintura de irmão Carlos, as águas descrevem a qualidade da vida na terra e também a ação dos homens sobre outros homens através da palavra que aconselha sua multiplicação. Palavra e figura se confirmam reciprocamente em mútua remissão alegórica: a intensificação das atividades proselitistas indicada pelo versículo bíblico está sendo descrita pela circulação 
em expansão das águas sobre a terra. O meio principal da vida no mundo pentecostal é a água-palavra proselitista: que se expande tanto num eixo horizontal - dos humanos para os outros humanos -, quanto num eixo vertical - da materialidade do mundo a sobrenatureza. Isso significa que nessa cosmologia o mundo é composto por forças, fluxos, processos. Em termos de agência, a pessoa que não se abre para esses fluxos da vida, ou seja, que não se abre voluntariamente para a "recepção do Espírito Santo", por um lado, não se realiza como pessoa - pois ignora sua participação neste cosmos em movimento -, e por outro lado, promove um impacto negativo na totalidade do mundo, pois nele diminui a presença do sagrado ${ }^{1}$.

Como já comentei anteriormente, a pintura pentecostal (Figura 2) não revela o reverso deste mundo, onde homens e mulheres são "pessoas do mundo", portanto, "filhas do pecado" e da "morte". Segundo Austin-Broos (1997), os pentecostais jamaicanos chamam os não crentes de "caminhantes-mortos-emvida", numa clara atribuição de perda do vínculo das alteridades com as "forças da vida" (1997:133ss).

Vale sublinhar que, enquanto a pintura de Rosina (figura 1) convive com um etnocentrismo razoavelmente acomodado no mito fundador - os católicos sabem como o mundo foi "naturalmente" constituído no início dos tempos - o etnocentrismo na pintura do irmão Carlos (Figura 2) relaciona-se com a suposição de que os crentes são capazes de apreender a qualidade "verdadeira" do meio que os seres humanos habitam. Ludibriados por seus próprios sentidos, as "pessoas do mundo" relacionam-se com o seu meio confundindo, digamos, as qualidades das "águas" pelas do "ar".

Enfim, as duas pinturas nos ensinam através de suas imagens que existe uma distância considerável entre as noções de salvação católica e pentecostal. O católico busca a salvação como quem busca a adequação em um mundo hierarquicamente constituído. Por mais que na modernidade, as coisas estejam "muito confusas" e as pessoas sejam atravessadas por uma avalanche de transformações sociais, culturais, morais e políticas ocorrendo em simultâneo, a ortodoxia católica não questiona a ordem da totalidade e os fiéis se engajam cada vez mais em eventos de Aparição Marianas e de videntes se dispondo a fazer mediação (Steil 2003).

Por outro lado, a salvação pentecostal envolve uma escolha individual ("Eu aceito Jesus Cristo") que interfere na economia total do mundo - são os crentes que formam as águas que garantem a continuidade da vida na terra. A imagem do mundo sem crentes não foi pintada pelo irmão Carlos, mas podemos supor que seja desértica, despovoada e sem vida. Nesse sentido, a salvação pentecostal não envolve encaixe mas preenchimento (da pessoa como vaso, do mundo como recipiente). 


\section{A trilha sacrificial e o "aguardo no Senhor"}

Para propor as continuidades e descontinuidades entre a análise anterior e o chão do cotidiano, vou recorrer a um expediente semelhante ao da primeira parte do artigo: vou investir nas idas e vindas de um artefato textual, uma passagem bíblica que tem sido central no debate sobre gênero entre católicos e pentecostais no Brasil. No acompanhamento da circulação do artefato, vou assumir a complexidade do fenômeno ainda que esta circulação se legitime no discurso da autenticidade: a extração de um fragmento de texto de um contexto e a recontextualização em outro pode remeter a lastros de tradição visíveis em um contexto e ocultos em outro.

A passagem que eu vou discutir está na carta aos Efésios, escrita pelo apóstolo Paulo, e que na Bíblia cristã recebeu o subtítulo de "moral doméstica" ou "os deveres domésticos". A passagem tem sido lida e relida nos encontros de casais, cursos femininos, seminários sobre vida familiar, sessões de aconselhamento de diferentes tradições cristãs no Brasil. Na Nova Bíblia de Jerusalém, em Efésios 5:22-24 lê-se: "As mulheres estejam sujeitas aos seus maridos, como ao Senhor, porque o homem é cabeça da mulher, como Cristo é cabeça da Igreja e o salvador do Corpo".

O texto inicia enfatizando a existência de uma ordem mais abrangente e pré-estabelecida. Refere-se às mulheres, que devem ser submissas aos seus maridos o que é equivalente a outra ordem, dos maridos, que devem ser submissos à igreja, o que é equivalente à submissão da igreja a Cristo. Trata-se de uma passagem que descreve uma corrente de hierarquizações e submissões no plano mundano, resultado de relações mais diretas e íntegras do primeiro termo em relação ao segundo, diante de uma ordem espiritual primária e fundadora. Podese afirmar que o texto provoca um choque no leitor moderno por postular a existência de uma ordem hierárquica onde supostamente a mesma já havia sido abolida: no interior da família, na relação igualitária do casal. Porém, enquanto o suposto leitor moderno tende a congelar diante da afirmação "as mulheres estejam sujeitas aos seus maridos", deixando de escutar o resto da sentença, leitores carismáticos e pentecostais seguem adiante celebrando o pressuposto de complementariedade. Uma jovem pentecostal de 22 anos explicou a passagem para a pesquisadora Camila Sampaio da seguinte forma: "O homem sem a mulher não é nada! Porque sem o pescoço a cabeça não tem sustentação... uma coisa complementa a outra. Por serem diferentes [o homem e a mulher], eles se complementam... no corpo, ninguém é mais que o outro" (Sampaio 2007:22). Nesse caso, para essa jovem, a hierarquia está subordinada ao valor da complementaridade entre os termos.

Etnografias desenvolvidas recentemente têm chamado atenção para articulações insuspeitas entre pressupostos de gênero hierárquicos e complementares da pessoa, 
mesmo em regiões de longa tradição católica. No interior do sertão nordestino, por exemplo, em Santa Lucia, cidade onde Maya Mayblin (2010) desenvolveu seu trabalho de campo, os católicos enfatizavam não tanto a diferença entre gêneros, mas a continuidade entre homens e mulheres por compartilharem uma condição de vida comum e de difícil compreensão. Naquela cidade, tanto os homens quanto as mulheres se identificavam por "lutarem" exaustivamente para "levar a vida". Mas eles não ignoravam as diferenças de gênero, em especial que os meninos devem investir em um conhecimento sobre como circular em um mundo de pequenos negócios, cujo impasse está em atualizar uma moral de justiça social sem, entretanto, deixar de ganhar o melhor na troca para prover os seus. Já na educação das meninas, desde cedo elas eram incluídas em uma rotina de pequenas e constantes tarefas desenvolvidas no sentido do cuidado dos outros.

Em sua etnografia, Maya Mayblin demonstra que em Santa Lucia a vida é um desafio tanto para homens como para mulheres. Entre as mulheres, inclusive, isso pode se desenvolver com uma forma narrativa específica, uma fala meio sussurrada, meio cantada, meio gemida, continuamente referida às preocupações, às insatisfações e aos sofrimentos. Trata-se da lamúria, um gênero narrativo que tende a ser acionado por mulheres e entre mulheres, e que pode seguir sem que o interlocutor preste atenção ou demonstre isso. Como verifica Maya Mayblin, na lamúria a falante vai abrindo um leque de situações que acabam por formar uma topografia que a coloca em uma posição sacrificial - em geral, um sacrifício implícito e sem enquadramento ritual: "dar a luz, cuidar dos filhos, lavar, alimentar, fazer escambo, carregar, limpar, rezar, se preocupar, carregar, limpar, rezar, se preocupar: isto é um sacrifício monótono e incompleto" (Mayblin s/d:6).

Além de se referir a um sacrifício sem retorno, a lamúria está ligada a uma socialidade peculiar: as vizinhas e conhecidas escutam umas às outras as suas lamúrias sem a expectativa de retorno ou diálogo. Inclusive, na etiqueta local, dificilmente os vizinhos conversam diretamente com o autor da lamúria, ainda que conversem entre si sobre a lamúria de um terceiro, procurando avaliar a integridade ou não do ato sacrificial em curso. Uma mãe que cumpre suas tarefas cotidianas pode ser louvada indiretamente. Já um silêncio respeitoso pairará sobre uma mãe que tenta o suicídio em função da depressão. Sobretudo, o elogio aberto é evitado, uma vez que isso implicaria a não realização completa do sacrifício, pois então ele deixaria de ser propriamente um sacrifício e se tornaria troca e busca de autoglorificação (cf. Keenan 2005). Por isso, de acordo com Maya, pode-se dizer que é tão importante para as católicas de Santa Lucia o compartilhamento do corpo de Cristo no ato eucarístico. O estabelecimento de uma continuidade material entre seu sacrifício cotidiano e o sacrifício divino garante os benefícios do alívio e do conforto. No reverso, palavras não são bem vindas nessa comunicação do plano humano e sobrehumano. 
Etnografias como a de Santa Lucia dão pistas preciosas sobre como tem sido feita a recepção de Efésios 5:22-33 entre católicos brasileiros, em especial, entre os habitantes de meios rurais e/ou mais tradicionais. Mesmo que haja uma oscilação entre a ênfase no assemelhamento - todos somos seres sofredores, independente do gênero - e seu aspecto diferenciante - as pessoas têm gêneros diferentes e por isso devem seguir sua vida cumprindo funções diversas - a ordem de "encaixe" em uma hierarquização de mundo primeva se sobrepõe às negociações e flexibilizações ao longo do caminho da vida. Há algo de "natural" que não pode ser mudado: a lamúria deve seguir sendo dita, e o sacrifício pode, por vezes, encontrar um consolo no abraço do divino, mas a sina humana segue como a de um caminho sacrificial em aberto. Em outras palavras, o contato com o sagrado revitaliza, mas dificilmente transforma a ordem da vida.

Quando minhas amigas crentes de Magé leram a mesma passagem bíblica, elas chamaram atenção para a segunda parte do texto. Na Bíblia do Estudo Pentecostal, do versículo 28 em diante está escrito:

Assim devem os maridos amar a sua própria mulher como a seu próprio corpo. Quem ama a sua mulher ama-se a si mesmo. Porque nunca ninguém aborreceu a sua própria carne; antes, a alimenta e sustenta, como também o Senhor à igreja; porque somos membros do seu corpo. Por isso, deixará o homem seu pai e sua mãe e se unirá à sua mulher; e serão dois numa carne (Ef. 5:28ss).

Entre as mulheres pentecostais, a ênfase recai não tanto no poder restaurador do retorno a uma ordem de mundo fundadora, mas na busca da constituição de uma relação de encadeamento metonímico perfeito, o que garantirá uma relação de assemelhamento quase andrógino no interior do casal.

Observe-se que encontramos na leitura de Efésios 5 um contraste de recepção do texto bíblico complementar ao contraste encontrado nas pinturas de Rosina e Carlos. Em vez de buscarem os vínculos com um tempo pretérito perfeito constituidor da humanidade e do mundo, como as católicas de Santa Lucia, as mulheres crentes projetam o sentido do versículo para um futuro que se abre como promessa. Para as crentes, o que seduz é o devir, a abertura para um caminho de vida onde homens e mulheres aprendem a desenvelopar a promessa divina de dois seres em um. No reverso: sem percurso de vida, não há gênero.

Para que o leitor tenha uma ideia mais clara da importância do caminho percorrido para a definição do gênero entre pentecostais, vou trazer duas narrativas. A primeira foi registrada por mim durante pesquisa em uma comunidade pentecostal de Magé, cidade da periferia do Grande Rio. É a história de Inácia e Magnair. A segunda foi narrada para Camila Sampaio 
(2007) em seu trabalho de campo em uma favela da Zona Sul do Rio de Janeiro, o Cantagalo. Trata-se dos relatos de Sônia e Aloísio (a pesquisadora faz uso de codinomes).

Vale ressaltar que a primeira história é a de um casal considerado exemplar na igreja de que participam, a Assembleia de Deus da Lagoa, em Magé. Esse é um caso sociologicamente relevante, pois segundo dados do Censo 2010, os pentecostais começam a se casar mais cedo que os católicos (entre 18 e 19 anos, $8,1 \%$ das mulheres eram casadas em contraste com a porcentagem de 2,9\% das católicas) e permanecem casados durante boa parte de sua vida (dos 30 anos em diante $54,5 \%$ das mulheres pentecostais estão casadas o que faz contraste com as 39,6\% de casadas católicas).

Em Magé, Inácia é considerada uma mulher que "veio de fora". Trazida pela mãe em 1973, ela migrou de João Pessoa, do nordeste, a convite de um tio materno. Segundo conta, sofreu muito nos primeiros anos. Aquilo que era promessa para uma garota de dez anos, se tornou um martírio prolongado. Como as migrantes eram "apenas" duas mulheres, para poder trabalhar, a mãe teve que deixar Inácia aos cuidados do tio, que recebeu a menina a contragosto. Em troca da acolhida, Inácia teve que trabalhar duro, realizando inúmeros serviços domésticos para a família numerosa. Nos primeiros anos, Inácia relembra, o tio a impediu de tomar banho: a água era valiosa; a menina, um "traste". Suja, surgiram algumas feridas pelo corpo. Dormindo em pelegos, as feridas de seu corpo grudavam no couro do leito, o que acabava por gerar infecções em sua pele. Sujeira, feridas, frio e fome eram uma constante. No dia que a prima caçula a acordou com um ferro em brasa marcando a sua pele feito gado, a mãe decidiu levar Inácia para a casa onde passara a morar, com o Polaco. A relação da mãe com o Polaco foi um arranjo: ele era viúvo e estava bem de vida. Tinha as filhas adolescentes e precisava de uma mulher. A mãe de Inácia topou o casamento e assim Polaco tornou-se seu padrasto. Se, na casa do tio, Inácia era tratada como escrava doméstica, na casa do padrasto, então desabrochando como mulher, ela passou a ser assediada sexualmente. Meninos espiando pelas frestas do banheiro, tentativas de roubo e estupro no quarto, perseguição assustadora de um homem encapuzado depois da aula. A fama de "mulher de vida fácil" de Inácia cresceu e tornou seu cotidiano infernal: ela sequer conseguia distribuir leite pela cidade, incumbência que realizava para o padrasto. Certo dia, diante da acusação direta do Polaco, a mãe resolveu pagar uma consulta particular no ginecologista da cidade, solicitando que a virgindade da filha fosse registrada em documento. Inácia guarda até hoje o papel com a descrição (cujo registro varia entre a linguagem técnica e o estilo barroco) de seu clitóris virgem.

Aos 18 anos, Inácia convidou Magnair para a sua formatura. Em 1983, dois anos depois, eles se casaram no civil. Na época, Magnair já se destacava 
como um excelente mecânico e conseguiu comprar um terreno onde construiu os primeiros cômodos da casa. Recém-casados, foram morar em uma casa que só tinha uma cama sem colchão e um guarda-roupa. Com muita dificuldade Inácia trabalhava no aviário e Magnair na mecânica -, os dois somaram os salários e conseguiram terminar a construção da casa e mobiliá-la em dois anos. Nessa época veio Carla, a primeira filha, e três anos depois, veio o caçula, Felipe.

A família foi levando a vida, com uma doença aqui, um sufoco ali, alguma festa no meio do caminho. Ao longo desse tempo, Magnair tentou de várias maneiras trabalhar por conta própria. A relação abusiva e autoritária dos donos de mecânica onde trabalhava, aliada ao alto valor da ideologia de "ser seu próprio patrão" em um país de passado escravagista, conduziam-no nessa direção. Em 1993, porém, essa ambição o levou ao desastre financeiro.

Dois anos antes, Magnair havia feito parceria com um ex-bancário para montar uma oficina no centro da cidade, em uma porta de garagem de propriedade do sócio. Nessa parceria, Magnair trabalhava na mecânica e Carlos cuidava da parte administrativa. Um era trabalhador manual, outro administrativo; um pegava no pesado, o outro cuidava do atendimento aos clientes; um era semi-analfabeto, outro tinha o Ensino Médio. Certo dia, Magnair chegou em casa para dar a terrível notícia: ele tinha perdido todos os bens. O sócio utilizara uma folha em branco para produzir um documento no qual Magnair cedia todos os seus bens em favor de Carlos.

Diante do desastre e da traição do amigo, o casal não esmoreceu. Eles decidiram "recomeçar do zero". Decidiram não pedir ajuda para um primo de Magnair, o vereador Batata. Venderam a geladeira, o som, e rasparam a poupança. Com isso, Magnair comprou novas ferramentas e alugou uma porta de garagem, inaugurando uma nova mecânica na cidade. Trinta anos depois, eles me apresentam o espaço que ocupam hoje na cidade de Magé, em um terreno em uma área nobre, perto da BR, com uma casa de três andares e uma oficina com capacidade de atendimento simultâneo de dois caminhões. Para completar, a filha mais velha, Carla, se prepara se candidatar a um concurso público para o cargo de delegada de polícia.

É importante dizer que a história de Inácia e Magnair se desenvolve em um contexto destradicionalizado: as expectativas convencionais de reciprocidade e proteção no interior da parentela não se cumprem; as expectativas de solidariedade e lealdade entre amigos não se realizam e são rompidas; os abusos e pequenas crueldades entre crianças e crianças e adultos são rotina.

Nesse contexto, o casal entrelaçou suas histórias individuais de modo contínuo e complementar: Magnair não tratou Inácia como escrava ou prostituta; e Inácia, sem uma história pregressa positiva com a sua parentela, também não se propôs a contestar as relações de parentesco do marido. Nessa narrativa, 
temos a sucessão de sacrifícios mutuamente complementares que vão se alinhando em direção a expectativas de autorrealização de um em dois.

Em 2009, quando entrevistei o casal, Inácia e Magnair eram gratos pela superação da trajetória pregressa - eles eram um dos casais mais prósperos da igreja que frequentavam - e teciam elogios recíprocos. Inácia afirmava que Magnair era atencioso com os seus empregados e correto no reconhecimento de direitos. Magnair afirmava que Inácia era uma pessoa "generosa demais, pois não podia ter dinheiro na bolsa que logo ia ajudando o irmão que precisasse".

Sugiro que a categoria "amor pentecostal" é adequada para descrever a relação de Inácia e Magnair mesmo que o casal não tenha utilizado o termo em sua narrativa. Em primeiro lugar, ao longo de sua trajetória de vida, Inácia e Magnair observaram-se reciprocamente procurando reconhecer o ponto de vista do outro e a aprender o seu movimento. Sublinho: foi ao longo do percurso que eles foram se conhecendo como dois; como dois que pretendem virar um; como partes que são fragmento e multiplicidade. Em segundo lugar, Inácia e Magnair, com ou sem hesitações, procuraram não impor cada qual sua vontade de modo definitivo sobre o outro, forçando-se mutuamente para além de suas inclinações. Nesse sentido, suas atuações recíprocas foram não violentas, e articuladas como dádivas gratuitas (mesmo que umas quantas vezes sem sucesso). Por fim, no devido tempo (e não antes) os dois se sentiram recompensados. Como pentecostais, o sacrifício que um fez em razão do outro está apoiado em uma promessa indicada em Efésios 5:22-33, de uma relação metonímica perfeita, onde homem e mulher unidos por um pacto de lei, metamorfoseiam sua cultura em natureza, alcançando a unidade perfeita da vida em dois como uma só carne. Inácia e Magnair buscaram a realização dessa promessa a partir de uma performance coordenada de atos sacrificiais com apoios convencionais do gênero masculino e feminino do entorno. Ao que parece, ao fazê-lo ao longo de seu movimento de vida, eles chegaram muito próximo de uma relação de androginia.

A segunda narrativa também se passa em um contexto destradicionalizado: trata-se de uma favela situada na zona sul carioca, em um período especialmente violento da vida local em função do aumento escalonado do tráfico de armas e de drogas na região. Além disso, essa narrativa nos aproxima de uma situação usual na história de vida das mulheres pentecostais que ficam "aguardando no Senhor". Ainda que estar sem companheiro seja uma situação cada vez mais corriqueira na vida de mulheres brasileiras ${ }^{2}$, minhas interlocutoras percebiam essa situação como algo passageiro: no futuro, elas encontrariam/resgatariam um companheiro.

Noto, porém, que a narrativa que segue não foi relatada depois dos mais de quinze anos do "aguardo do Senhor", um tempo que Sônia teve que transcorrer até a conquista completa de seu marido. Quando Camila Sampaio (2007), a pesquisadora, registrou a narrativa, o intervalo de tempo já estava justificado no 
resultado "feliz". Outras mulheres que não têm o mesmo resultado devem obviamente construir a narrativa de outro modo, talvez ampliando o tempo do "aguardo no Senhor", talvez reestruturando o eixo da narrativa na aceitação do estado solitário, talvez abandonando a fé pentecostal.

No relato dado por Aloísio e Sônia, não fica claro o ano em que eles se conheceram. O certo é que, na época, Aloísio já tinha tido vários relacionamentos amorosos. Fruto dessas relações, ele tinha dois filhos com duas outras mulheres. Com Sônia, entretanto, ele prometia uma "vida diferente". O casal procurou se organizar segundo um padrão tradicional na favela do Cantagalo: ele seria o provedor, ela seria a mãe e cuidadora do lar. Aderindo a esse padrão convencional de estruturação dos papéis de gênero, o casal teve quatro filhos. Porém, desde o início surgiram conflitos: Aloísio parecia não conseguir se livrar do enorme prazer da conquista de amantes fora de casa. De uma forma ou outra, Sônia sempre ficava sabendo dos casos extra-conjugais. Mesmo assim, ela cumpria com sua obrigação:

Ele podia arrumar a mulher que fosse, mas no final sempre voltava prá mim. Ele nunca chegou em casa e não tinha comida. Sempre tinha um prato feito para ele, a casa arrumada, as roupas limpas (Entrevista de Sônia apud Sampaio 2007:34).

Ao longo de vários anos de seguidas traições, Sônia procurou forças na igreja. Mais tarde, cansou de suportar o adultério do marido sem reagir aberta e agressivamente e resolveu sair da igreja. Fora da igreja, podia brigar e constrangê-lo mais diretamente. Isso, porém, não fez Aloísio mudar de comportamento. Pelo contrário, ele teve outros três filhos com outras duas mulheres. Mesmo assim, seguia, ao menos formalmente, morando com Sônia, que depois de dez anos desviada, retornou à igreja. Dessa vez, Sônia passou a frequentar a igreja Maranata, uma denominação mais flexível nos "usos e costumes". A filha mais velha gostava de lá. Sônia voltou a orar pelo marido, participar de campanhas por ele, pedir conselhos ao pastor. De tanto insistir, Aloísio passou a frequentar a igreja com a família.

Eu comecei a frequentar a Maranata. Na época, eu tinha uma amante. Eu falei assim 'Olha, eu to largando você. Eu to largando!' Porque o Espírito Santo tava trabalhando na minha vida. Por exemplo, eu ia pros motéis, às vezes eu me drogava a noite toda. Chegava de manhã, eu caía naquele arrependimento. Aquela coisa terrível! Uma dor que vinha no meu coração. Eu sentia que: 'Poxa, eu fiquei aqui a noite toda vendo você fazer isso, aquilo'[...] Aquilo mexeu comigo. Quando chegava sexta-feira, eu já tava achando um 
transtorno. Já não era mais legal. Já não era mais como antigamente. Porque eu ficava pensando: 'Poxa, amanhã de manhã, Jesus vai vir no meu quarto, vai ficar me abraçando e eu vou ficar chorando igual uma criança'. Aquilo tava gerando em mim um negócio muito ruim em relação às drogas, em relação ao adultério, em relação à bebida. [...] Foi duro largar: a bebida, as drogas e principalmente as mulheres! (Entrevista de Aloísio apud Sampaio 2007:56; grifos meus).

Segundo conta, a inquietação começou a rondar Aloísio quando ele passou a se ver acompanhado pela sombra de uma visada exterior, num olhar que não era nem conivente nem desinteressado. Foi o Espírito que "começou a trabalhar" e que passou a promover de modo irresistível a imagem de um interlocutor externo que avaliava as ações de Aloísio em relação ao seu próprio comprometimento afetivo.

Sônia relata o mesmo movimento de inflexão de Aloísio, reproduzindo a partir de seu lugar o diálogo que Aloísio teria enfrentado interiormente:

Ele saía na quinta, voltava no domingo. Mas aí o pastor conversava, falava com ele. Um dia ele falou: "Vou mudar! Um dia eu vou mudar, eu vou largar tudo isso! Isso está um castigo! Eu tô cansado. Eu não quero mais! Não dá mais! Eu tenho a vida que eu queria ter. Eu tenho um trabalho. Tenho quarto filhos". [...] Aí ele começou a sair fora de uma outra relação com uma mulher. "Já não quero mais!”. Começou a frequentar a igreja (Entrevista com Sônia apud Sampaio 2007:56).

Neste fragmento, Sônia utiliza o discurso indireto livre, num modo de narrar em que o ouvinte se vê e se imagina através dos olhos e pensamento do outro. Durante muitos anos, Sônia seguiu as pegadas do marido, acompanhou suas idas e vindas, auscultou seus pensamentos, explorou os subentendidos de suas falas, observou seu gestos e hesitações, pedindo a Deus e ao pastor por ele. Parece-lhe natural recontar a história do marido confundindo-se com o lugar de fala dele. Isso, contudo, não quer dizer que Sônia abandonou sua própria identidade, interesses, direitos e deveres. Entre tantas mulheres que o marido teve, ela cultivava a esperança de que, como decisão final, Aloísio ficasse ao lado dela e de sua família. Quando eles relataram suas histórias para a pesquisadora, em 2006, tudo parecia indicar que esse tempo chegara. Aloísio tinha largado a vida do "mundo" e se dedicava, então junto com Sônia e a família, ao trabalho como pastor presidente da Assembleia de Deus Restaurando Vidas. 
Nessa trajetória, Sônia parece ter sustentado os mesmos princípios do "amor pentecostal" que encontramos na narrativa de Inácia e Magnair. Primeiro, o marido sempre esteve lá no "olho da sua mente". Sônia, ao longo de sua trajetória, procurou pensar e agir como Aloísio, reconhecer o seu ponto de vista e aprender a se movimentar como ele. Em outras palavras: a alteridade amorosa foi apreendida em sua movimentação, seus fluxos, suas hesitações, seus percursos. Noto que, como durante muito tempo não havia cooperação entre o casal, isto era feito como um jogo de esconde-esconde: muita coisa não dita, muita coisa em segredo. Em segundo lugar, por mais que Aloísio estivesse fora do padrão de marido socialmente aceito no Cantagalo, Sônia procurou não impor sua vontade de modo definitivo, forçando-o a mudar o comportamento contra suas próprias inclinações. Esse é o princípio da não violência, que deve ter sido mais difícil sustentar, pois exigiu que Sônia abrisse mão da expectativa de reciprocidade ao longo de todo o tempo de espera: "Sempre tinha um prato feito para ele". Por fim, Sônia se sentiu recompensada: no devido tempo (e não antes) o marido se revelou à esposa e se doou graciosamente a sua vontade. O tempo do "aguardo no Senhor" tinha terminado com um final feliz.

Podemos supor que muitas situações semelhantes a esta do casal Sônia e Aloísio ocorrem em contextos destradicionalizados. As expectativas de que duas pessoas que se juntam amorosamente para se "encaixarem" perfeitamente podem ser facilmente frustradas, cabendo ao futuro projetado em cor-de-rosa um fel de experimentação de distâncias, conflitos e desgastes. A cosmologia pentecostal e a noção de salvação incluem essas disputas entre dois como parte relevante do percurso, ainda que, se houver um "final feliz", os momentos difíceis sejam depois lembrados como apenas um "tempo de tribulação" - ou seja, um intervalo temporal que carrega um sentido que não é o do evento em si.

Chamo atenção para a capacidade de resiliência das mulheres pentecostais nesses desencontros amorosos. Mesmo com experiências de vida em comum fortemente marcadas pelo conflito com a alteridade, as mulheres podem seguir "aguardando no Senhor" em uma espera que pode se alongar por muitos anos, às vezes, décadas. Ao tratar esse tempo de espera como o "aguardo no Senhor", essas mulheres tendem a tratar o presente (em geral, conflituoso) como um tempo que será experimentado e esquecido em relação a um final que cumpre o desejo, por exemplo, de complementaridade harmônica entre dois: quando está no "aguardo no Senhor", a mulher se projeta em direção a um futuro auspicioso (o encontro de dois em um, por exemplo) que não existe no presente; o futuro almejado está, aliás, anunciado nas escrituras, tendo sido prometido por Deus. Portanto, para a resiliência pentecostal é fundamental a confiança no Deus Amoroso, que preserva uma aliança com a humanidade. Sobretudo, através dessa resiliência as mulheres pentecostais brasileiras demonstram a sua superioridade em relação às mulheres não crentes, incapazes de uma 
demonstração de amor culturalmente tão fora dos limites do humano e tão próxima da noção de Saintliness.

Aparentemente, a expressão "aguardar no Senhor" também circula entre as fiéis da IURD em Moçambique (Van de Kamp 2011), porém, se seguirmos a etnografia de Linda, seu sentido é diferente. Em Maputo, parece ser um jargão utilizado pelas jovens que participam da "Terapia do Amor", indicando sua expectativa que, seguindo a disciplina da igreja, "encontrem o futuro marido".

Segundo Linda van de Kamp, em Moçambique, desordens no casamento e na vida do casal geralmente são atribuídas à ação de ancestrais: alguma dívida de "lobolo"3" não paga; alguma gravidez que não vai adiante por interferência do espírito da tia morta ressentida; o pagamento do enriquecimento súbito com a aliança com o "marido espiritual" (Van Kamp 2011). A interlocução com os ancestrais é muito ativa e frequente entre moçambicanos rurais ou urbanos, ricos ou pobres, homens ou mulheres, onde quase tudo pode ser negociado a qualquer tempo (Costa 2005). Como hoje em dia estas negociações estão sofrendo enormes mudanças em função dos processos de migração e de modernização da sociedade, as pessoas não sabem quais são os poderes que controlam suas vidas e há uma sensação muito grande de incerteza e de insegurança no ar. Nesse contexto, é muito difícil traduzir adequadamente a noção de "aguardar no Senhor" que as mulheres pentecostais brasileiras tanto prezam.

No reverso, o contraste com a conversão em Moçambique ajuda a compreender a relevância, no contexto brasileiro, da crença em uma fonte total e absoluta de Amor Divino (Saintliness) para que o ritual do "aguardo no Senhor" se renove por tempos longos (vários anos ou décadas), apesar da contradição da experiência de vida presente. Os cristãos moçambicanos parecem ter dificuldades em crer na atuação mundana de um Deus Soberano e amoroso - esse ser que ao mesmo tempo protege e se ausenta. Além disso, o amor romântico é uma novidade inclusive na cultura pop regional. Muitos moçambicanos acompanham com avidez o desenrolar de melodramas das novelas brasileiras e mexicanas na televisão, aprendendo com os programas estrangeiros as voltas e reviravoltas dos caminhos do coração dos personagens. Sem a crença no Deus Amoroso, na Saintliness, a promessa de Efésios 5 (de um homem e uma mulher convivendo amorosamente) dificilmente se completará, pois a aposta cega em um futuro promissor apesar do presente conflituoso, não encontrará justificativa cultural. Nesse contexto, será muito mais razoável que ao longo do percurso os antepassados tenham algo a dizer de acordo com as tradições e o interesse étnicos, regionais e afetivos diferentes, implodindo, por dentro, uma comunicação hesitante, complexa e íntima do casal ${ }^{4}$. 


\section{Considerações finais}

Termino fazendo uma breve consideração sobre o momento em que este artigo é escrito. No Brasil, nas últimas décadas houve um deslocamento da relação entre religiões e direitos humanos, especialmente em função da mudança da pauta do debate sobre direitos humanos: passou-se de um debate centrado nos direitos políticos e sociais para uma ênfase nos direitos individuais e sexuais. Temas como aborto, parceria civil entre pessoas do mesmo sexo, criminalização da homofobia, eutanásia foram discutidos publicamente, em geral, a partir de propostas de mudanças da legislação. Como protagonistas no embate, os atores religiosos foram identificados por pesquisadores como "grupos conservadores que atuam organizadamente a fim de impactar e obstruir demandas da sociedade civil", como pessoas que, guiadas por "valores religiosos", colocam-se contra as "liberdades individuais" (Gomes 2009:19). Em especial, observa-se muito criticamente a atuação da Igreja Católica, que se norteia pela defesa de uma "lei natural", indiferente à diversidade de opinião e de opção sexual: "Se a Igreja Católica pôde lidar no período militar com o dissenso político [...], parece não conseguir hoje lidar com o dissenso moral, excluindo da comunidade católica tanto os defensores da descriminalização do aborto quanto os gays" (Steil e Toniol 2012:91).

Neste artigo não abordei a posição de lideranças religiosas e de suas instituições. Em vez disso, procurei demonstrar a complexidade das concepções das populações católicas e pentecostais a partir de alguns objetos culturais, ainda que (ou justamente porque) essas posturas estejam alicerçadas em uma cosmologia baseada na "lei natural" e no "princípio bíblico". Do meu ponto de vista, ao longo do desenvolvimento do embate público sobre direitos individuais, a imagem da posição dos atores em função da contraposição foi se simplificando em demasiado, e ao fim, ser religioso se tornou sinônimo de sectarismo e contradição com as "liberdades individuais".

Por que direitos individuais e religiosos se excluiriam no cenário contemporâneo quando os direitos religiosos estão na origem da conquista de direitos individuais no Ocidente (cf. Taylor 2007)? Penso que isso tem a ver com uma recepção quase acrítica das teorias desconstrucionistas. Judith Butler, por exemplo, propõe que encaremos o gênero como performance e como paródia. Com isso, ela propõe ir além da crítica feminista de Simone de Beauvoir, que sublinha o aspecto culturalmente negociado da constituição dos gêneros. Para Butler, Simone de Beauvoir demonstrou adequadamente que os gêneros são fabricação, porém, se apequenou em relação às consequências da afirmação, pois se "os gêneros não são nem verdadeiros nem falsos, e produzidos como efeitos de verdade de um discurso sobre a identidade primária e estável" (Butler 2012:195), o interessante seria aceitar permanecer na oscilação em vez de 
constituir algo "entre", nem feminino/nem masculino. A paródia envolveria essa constituição de identidade que é um deslocamento perpétuo, que não se relaciona com nenhuma noção de originalidade.

Eu acredito que a posição desconstrucionista de Butler tem o mérito de questionar até o limite a pretensão de verdade da constituição do gênero porém, em sua crítica ela supõe que todos os gêneros são performance e se equivalem em sua busca paródica. Baseada em dados etnográficos, sugiro que enquanto alguns modos de constituição de gênero podem se realizar como contestação a um original, outros se realizam precisamente por uma performatização da relação com um original. Católicos e pentecostais, como vimos anteriormente, não pretendem se colocar como "autores" originais do gênero que vierem a constituir, e preferem se reconhecer como "testemunhas" da palavra bíblica e "imitadores" de Cristo. Em especial, o dualismo processual pentecostal e carismático se realiza em relação a uma promessa futura. Enquanto na busca do gênero como paródia, a performance de gênero se faz em uma remissão aberta e sem controle a uma multiplicidade de fontes, o percurso de constituição de gênero entre os pentecostais só será pentecostal se submetido a um efeito de controle a partir de uma fonte (a palavra bíblica articulada a partir de uma determinada cosmologia).

Enfim, posso concordar que toda a identidade de gênero envolve uma experimentação em movimento, muita oscilação, muito ir e vir sobre o que compõe o feminino e o masculino. Uma diferença de fundo, porém, persiste, pois as várias versões de gênero dos pentecostais e dos católicos serão produzidas para serem "testadas" em relação a "fontes de controle": tais pessoas serão "imitadores de Cristo" ou "testemunhas do Deus Amoroso"? Isso, do meu ponto de vista, sustenta uma distinção relevante de procedimentos na constituição dos gêneros.

\section{Referências Bibliográficas}

AUSTIN-BROOS, Diane. (1997), Jamaica Genesis: Religion and The Politics of Moral Orders. Chicago: Chicago University Press.

BUTLER, Judith. (2012), Problemas de gênero - feminismo e subversão da identidade. Rio de Janeiro: Civilização Brasileira.

CANNELL, Fenella. (2006), The Anthropology of Christianity. Durham: Duke University Press.

COSTA, Ana Bénard da. (2005). "Famílias na Periferia de Luanda e Maputo: histórias e percursos nas estratégias actuais”. In: T. Cruz e Silva et. Al. 'Lusofonia' em África - História, Democracia e Integração Africana. Dakar: Codesria.

DUARTE, Luiz F. D. et al. (2009), Valores religiosos e legislação no Brasil - a tramitação de projetos de lei sobre temas morais controversos. Rio de Janeiro: Faperj \& Garamond.

FILKENSTEIN, Lucien. (2001), Brasil Naif. Arte Naif: testemunho e patrimônio da humanidade. Rio de Janeiro: Novas Direções.

FRESTON, Paul. (2010), "As duas transições futures: católicos, protestantes e sociedade na América Latina". Ciências Sociais e Religião, v. 12 nº 12: 13-30.

GOMES, Edlaine. (2009), "A religião em discurso: a retórica parlamentar sobre o aborto". In: L. F. 
D. Duarte et al. Valores religiosos e legislação no Brasil - a tramitação de projetos de lei sobre temas morais controversos. Rio de Janeiro: Faperj/Garamond.

INSTITUTO BRASILEIRO DE GEOGRAFIA E ESTATÍSTICA. (2010), Censo Demográfico 2010. Características da população e dos domicílios - resultados do universo. Rio de Janeiro: IBGE.

KAMP, Linda. (2011), Violent Conversion. Brazilian Pentecostalism and the Urban Pioneering of Women in Mozambique. Amsterdam: Faculty of Social Sciences, VU University Amsterdam.

KEENAN, Dennis. (2005), "A genealogy of Theories of Sacrifice". The Question of Sacrifice. Bloomington: Indiana University Press.

MAFRA, Clara. (2002), Na posse da palavra. Religião, conversão e liberdade pessoal em dois contextos nacionais. Lisboa: Imprensa de Ciências Sociais.

(2011), "Saintliness and Sincerity in the formation of Christian Person". Ethnos, v. 76, $\mathrm{n}^{\mathrm{0}}$ 4: 448-68.

. et al. (2012), "O projeto pastoral de Edir Macedo - uma igreja benevolente par indivíduos ambiciosos?". Revista Brasileira de Ciências Sociais, vol. 27, n. 78: 81-96

MARIZ, Cecília. (2003), "Rainha dos anjos: a aparição de Nossa Senhora em Itaipú, RJ". In: C. Steil et al. Maria entre os vivos - reflexões teóricas e etnografias sobre aparições marianas no Brasil. Porto Alegre: Editora UFRGS.

MAYBLIN, Maya. (s/d), The Untold Sacrifice: The Monotony and Incompleteness of Self-Sacrifice in Northeast Brazil. Mimeografia.

(2010), Gender, Catholicism, and Morality in Brazil - Virtuous Husbands, Poweful Wives. New York: Palgrave Macmillan.

MONTEIRO, Douglas Teixeira. (1975), "Sobre os dois caminhos". Cadernos do ISER, v. 5: 21-9.

REESINK, Mísia. (2003), "Nossa Senhora de Anguera, Rainha da Paz e do mundo católico contemporâneo". In: C. Steil et al. Maria entre os vivos - reflexões teóricas e etnografias sobre aparições marianas no Brasil. Porto Alegre: Editora UFRGS.

ROBBINS, Joel. (2004), "The Globalization of Pentecostal and Charismatic Christianity". Annual Review of Anthropology, v. 33: 117-43.

SAMPAIO, Camila. (2007), "Remido pelo espírito", no comando da vida: trajetórias de líderes pentecostais em uma favela carioca. Rio de Janeiro: dissertação de mestrado em Ciências Sociais, PPGCS/UERJ.

SEGAL, Alan. (2004), Life After Death - A History of The Afterlife in Western Religion. New York: Doubleday.

STEIL, Carlos e TONIOL, Rodrigo. (2012), "A trajetória dos direitos humanos na Igreja Católica no Brasil: do discurso político ao discurso moral". In: P. Oliveira e G. Mori (orgs.). Mobilidade religiosa - linguagens juventude, política. São Paulo: Editora Paulinas.

SMILDE, David. (2012), Razão para crer: agência cultural no movimento evangélico latino-americano. Rio de Janeiro: Eduerj.

TAYLOR, Charles. (2007), A Secular Age. Cambridge: The Belknap Press/ Harvard University Press. VEYNE, Paul. (2007), Quand notre monde est devenu chrétien (312-394). Paris: Bibliothèque Albin Michel.

VICENTE DA SILVA, Andreia. (2011), "Ritualizando o enterro e o luto evangélico: compartilhamento e incomunicabilidade na experiência da finitude humana". Rio de Janeiro: Tese de doutorado em Ciências Sociais, PPCIS/UERJ.

\section{Notas}

1 É importante notar que com a ajuda das pinturas estou apontando o contraste entre as noções de salvação de católicos e de pentecostais brasileiros, dando pouca atenção às semelhanças e continuidades. Essa acentuação das diferenças tem a ver com o exercício heurístico que estou levando a termo. Não ignoro que no dia-a-dia as pessoas utilizam os referenciais das duas tradições religiosas, 
articulando-as dos modos mais surpreendentes e inusitados. Penso, por exemplo, que as aparições marianas, que podem ser interpretadas como situações de "transe católico" (Steil 2003), oferecem um sistema de circulação entre mundos bastante próximos ao dos pentecostais descritos aqui, justamente porque Maria é a figura sagrada mais próxima da humanidade. Entre outros aspectos, como Mísia Reesink (2003) e Cecília Mariz (2003) argumentam, as aparições marianas vêm para oferecer consolo aos homens diante de um mundo onde o mal se faz cada vez mais visível e ativo. A multiplicação das aparições marianas ao longo das últimas décadas seria, neste sentido, sintoma e evidência do catolicismo no mundo moderno e tem grande poder de transformação. Já a expansão da atuação do Espírito Santo no mundo carismático católico brasileiro, tende a se realizar dentro de uma criatividade transformacional mais restrita: a atuação do Espírito Santo deve se dar de modo "ordenado" como prescreve a CNBB, ou seja, deve se submeter à ortodoxia oficial sob o custo de se assemelhar demasiado com os pentecostais.

2 Por exemplo, o Rio de Janeiro é o estado que mais concentra mulheres solteiras, com o índice de 24\% (IBGE 2010).

3 "Lobolo" é o termo utilizado pelos moçambicanos para se referir às trocas que acontecerão entre a família do noivo e a família da noiva para consumar o casamento. Trata-se do dote. Segundo Costa (2005), esse costume tem mudado muito nos últimos tempos em uma Moçambique que se moderniza, mas segue muito pertinente na vida coletiva.

4 A etnografia desenvolvida por David Smilde (2012) em Caracas, na Venezuela, onde o pentecostalismo atrai mais homens que mulheres, fornece outras pistas instigantes sobre o entrelaçamento entre conversão, dualismo processual e caminhada em um percurso de vida que faz o gênero. Segundo David, em uma Venezuela em "crise", eram os homens das camadas populares que tinham redes sociais mais curtas e menos consolidadas com o entorno que aderiam mais facilmente ao pentecostalismo, afastando-se de referenciais de masculinidade socialmente consolidados. Em diálogo com David, Diana Lima (comunicação oral) sugeriu que a possibilidade de construção de uma noção de masculinidade alternativa crente tem relação com a possibilidade de reconhecimento cultural ampliado da coragem do homem crente que, apesar da experiência de vida presente, persiste na busca de manutenção dos vínculos amorosos com a família nuclear. Proponho que algo semelhante ocorre entre as mulheres crentes brasileiras que podem afirmar sua superioridade por sua coragem de "aguardar longos tempos no Senhor".

Recebido em janeiro de 2012 Aprovado em junho de 2012

Clara Mafra (claramafra@uol.com.br)

Doutora em Antropologia Social pelo Museu Nacional (UFRJ), com pósdoutorado na Universidade de Aberdeen (2002) e na Universidade da California (2010). É professora associada junto ao Programa de Pós-Graduação da Universidade do Estado do Rio de Janeiro e pesquisadora do CNPq. Autora de vários artigos e dos livros $\mathrm{Na}$ Posse da Palaura (Imprensa de Ciências Sociais) e Os Evangélicos (Jorge Zahar). Organizou, junto com Ronaldo de Almeida, a coletânea Religiões e Cidades - Rio de Janeiro e São Paulo (Terceiro Nome). 
Resumo:

O percurso de vida que faz o gênero: reflexões antropológicas a partir de etnografias desenvolvidas com pentecostais no Brasil e em Moçambique

Neste artigo eu retomo o debate em torno da "Batalha Espiritual" relacionando-a com a constituição de gênero entre os pentecostais. Apoiada em dados etnográficos, eu argumento que uma compreensão mais nuançada do dualismo pentecostal deve incluir, além de um processo de negociação na relação com a alteridade, a performance de uma relação com uma "fonte original" uma vez que, muito explicitamente, os pentecostais não identificam a si mesmos como "autores" da pessoa que constituem, mas como "testemunhas" da palavra bíblica e "imitadores" de Cristo.

Palavras-chave: Gênero, Performance, Circuito Atlântico, Pentecostalismo, Cristianismos.

\section{Abstract:}

The life path that makes gender - anthropological reflections based on ethnographic research among Pentecostals in Brazil and Mozambique

In this article I return to the debate on the cosmology of the "Spiritual Battle" relating it to the constituting of gender among Pentecostals. Supported by ethnographic data, I argue that a more nuanced understanding of Pentecostal dualism should include, as well as the on-going negotiations founded on relations with alterity, the performance of the relation with an "original source" since, very explicitly, the Pentecostals do not identify themselves as "authors" of the person constituted by them, but claim that they are "witnesses" of the biblical word and "imitators" of Christ.

Keywords: Gender, Performance, Atlantic Circuit, Pentecostalism, Christianities. 